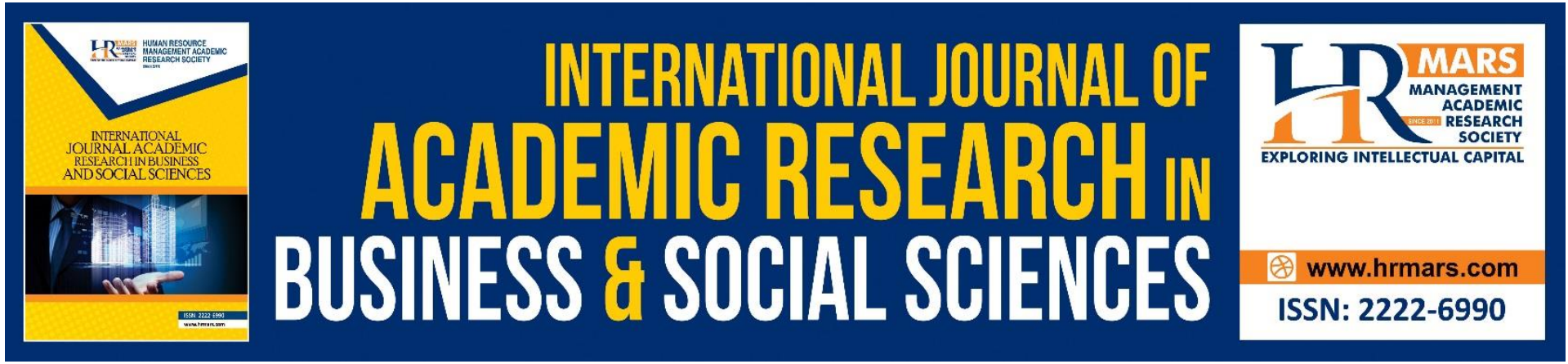

\title{
Unleashing Youth Leadership Qualities through Mentoring
}

Mohd Mursyid Arshad, Ismi Arif Ismail, Siti Feirusz Ahmad Fesol

To Link this Article: http://dx.doi.org/10.6007/IJARBSS/v11-i8/10788

DOI:10.6007/IJARBSS/v11-i8/10788

Received: 09 June 2021, Revised: 12 July 2021, Accepted: 30 July 2021

Published Online: 22 August 2021

In-Text Citation: (Arshad et al., 2021)

To Cite this Article: Arshad, M. M., Ismail, I. A., \& Fesol, S. F. A. (2021). Unleashing Youth Leadership Qualities through Mentoring. International Journal of Academic Research in Business and Social Sciences, 11(8), 930-946.

Copyright: (c) 2021 The Author(s)

Published by Human Resource Management Academic Research Society (www.hrmars.com)

This article is published under the Creative Commons Attribution (CC BY 4.0) license. Anyone may reproduce, distribute, translate and create derivative works of this article (for both commercial and non-commercial purposes), subject to full attribution to the original publication and authors. The full terms of this license may be seen at: http://creativecommons.org/licences/by/4.0/legalcode

Vol. 11, No. 8, 2021, Pg. 930 - 946

Full Terms \& Conditions of access and use can be found at http://hrmars.com/index.php/pages/detail/publication-ethics 


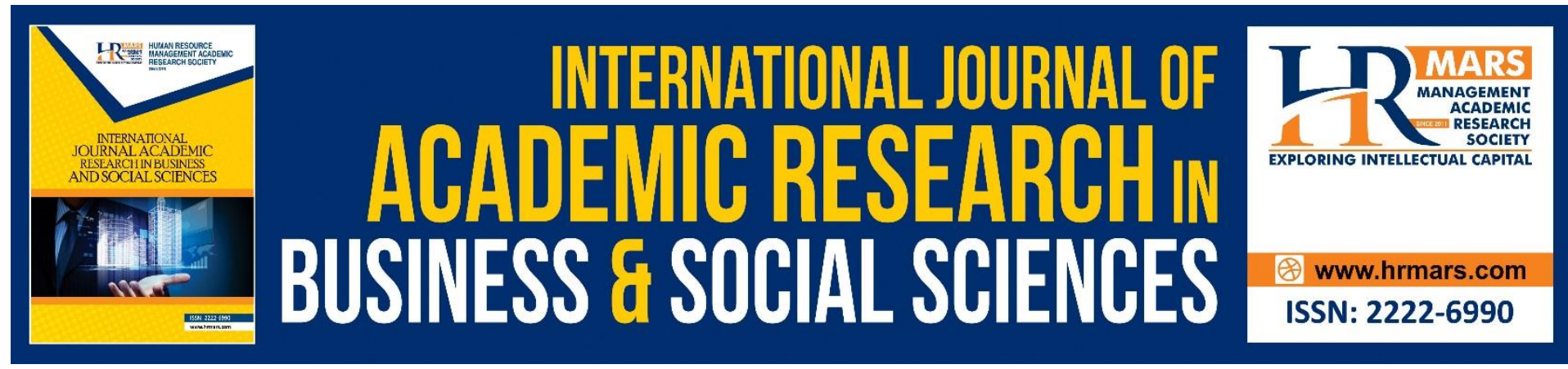

\title{
Unleashing Youth Leadership Qualities through Mentoring
}

\author{
Mohd Mursyid Arshad, Ismi Arif Ismail \\ ${ }^{1}$ Institute for Social Science Studies Universiti Putra Malaysia, 43400, Serdang, Selangor Darul \\ Ehsan, Malaysia \\ Email:m_mursyid@upm.edu.my, ismi@upm.edu.my
}

\section{Siti Feirusz Ahmad Fesol}

${ }^{2}$ Faculty of Computer Science and Mathematics, Universiti Teknologi Mara (Melaka), Jasin Campus, 77300 Merlimau, Melaka, Malaysia

Email: feirusz@uitm.edu.my

\begin{abstract}
Youth leadership is needed in nation building agenda and involvement of youth leader can be enhanced through wider exposure and professional training, including via mentoring. This paper discusses the potential of mentoring on positive youth development through the help of the Positive Youth Development (PYD) approach, which provides the theoretical basis for developing youth potential (Lerner et al., 2015; Shek et al., 2019), essentially requires empirical investigations to unleash youth leader potentials by mentoring. The study was conducted using a qualitative approach informed by the case study paradigm. This study found that mentoring provides opportunity to communicate directly between protégé and mentor and allowing learning through the organizational members. In conclusion, protégé is not only limited to the mentor, but learning process also occurred through organizational members. The qualitative findings provide insight that mentoring clearly has the potential to constitute the process of leadership learning through the PYD and provide the opportunity for youth to learn to become better leaders and better individuals.
\end{abstract}

Keywords: Youth, Leadership Qualities, Mentoring

\section{Introduction}

As a learning process, mentoring has been shown to enhance youth development outcomes such as raising the competence of youth leaders. Notwithstanding the challenges of mentoring, policy-makers of youth development programmes should highlight its benefits. In Malaysia, youth leadership development is a primary focus in Malaysia's development agenda as outlined in the Malaysian Youth Policy 2015 initiative. In line with the vision of becoming a developed nation, the Malaysian Youth Policy 2015 aims to strengthen the leadership development process among youth so that the nation will rank among the top countries in the world in terms of economic development, citizen well-being and innovation. The aspects of leadership must also be understood as a component of the guiding structure. Power can be 
acquired through the study of psychology, which encompasses social, mental, and physical dimensions. In terms of contact, intellect, spirit, and mind, assist in the development of a more principled through superior personality (Johar et al., 2020),

According to Zeldin et al (2017), most of youth leaders often do not see themselves as decision-makers because some adult leaders fail to adequately pass on the skills, experience, opportunities and motivation needed to lead. Moreover, the process of nurturing youth leadership through service-learning may inhibit young leaders from actively participating in the community development process, thus resulting in youth leaders lacking a sense of connection to their communities (Christens \& Dolan, 2011; Khan et al., 2019). Findings from the most recent Malaysian Youth Index (2019) indicate that this is currently the situation in Malaysia, i.e. youth's readiness to lead is decreasing. In addition, there are concerns about the ability of Malaysian youth to lead. The situation is compounded by the fact that the government through Malaysian Youth Policy 2015 and an amendment to the Youth Societies and Youth Development Act 668 (2019) has formally re-classified youth as those between 15 to 30 years, compared to the previous range of 15 to 40 . With a younger cohort of youth leaders taking on formal leadership roles within the country in the near future, there is much concern regarding the leadership readiness of this group.

Researchers and practitioners concur that the involvement of young leaders in nation-building can be strengthened through wider exposure and professional training, as well as through mentoring. Scholars contend that youth leadership development requires participative learning and role models that can be emulated (Redmond \& Dolan, 2016). According to Seemiller (2018), youth involvement in leadership activities is central to the youth development process through participation in organization or engage in school-based extracurricular activities. However, youth leadership development requires facilitated learning and exemplary role models. Kay and Hinds (2012) suggest that mentoring has the potential to provide such a learning process. Therefore, this study was conducted to explore how mentoring-based leadership development programmes could enhance the mentee's sense of connection to the community and youth stakeholders. The mentoring process investigated in this study involved input from mentors and the Ministry of Youth and Sports Malaysia as the programme planner and mentoring provider.

\section{Positive Youth Development}

Positive youth development (PYD) rests on two main concepts. The first is that youths possess inherent strengths or assets that form the foundation of their cognitive, emotional, social and behavioural development (Phelps et al., 2009; Gestsdottir et al., 2011). Second, their wellbeing will be enhanced when their strengths are compatible with, and facilitate, appropriate behavioural reactions to their surroundings (Benson et al., 2006), resulting in positive development. The individual development process in the PYD context involves adaptation of developmental regulations between youth strengths and asset development within a particular ecology (Phelps et al., 2009).

The PYD perspective stems initially from a positive psychological concept, the result of comparisons made by psychologists and biologists studying plasticity in the human development process. Specifically, the PYD perspective may be encapsulated in the following statement: 
"The Positive Youth Development (PYD) perspective is an orientation to young people that has arisen because of interest among developmental scientists in using development systems, or dynamic models of human behaviour and development for understanding the plasticity of human development and the importance of relations between individuals and their real-world ecological settings as bases of variation in the course of human development"

(Sibereisen \& Lerner, 2007, p.3)

The term 'plasticity' implies potential for more systematic changes in human development (Lerner et al., 2005; Lerner, Brittian \& Fay, 2007). The process requires internal and external support. According to Theokas (2005), the combination of internal and external situations for the development of PYD elements mentioned above are known as individual and ecological assets (Lerner et al., 2012). The internal asset is an element that guides youths to make choices related to their strengths, hopeful future expectations, internal self-regulation and positive school engagement. Meanwhile, the external assets are ecological assets mostly related to positive experiences obtained from others, and the institutions they are involved with (Lerner et al., 2012). Joint benefit could arise from the individual and ecological assets in the context of their relationship with PYD through five elements ('5 Cs') (Lerner et al., 2005), as illustrated in Figure 1 below

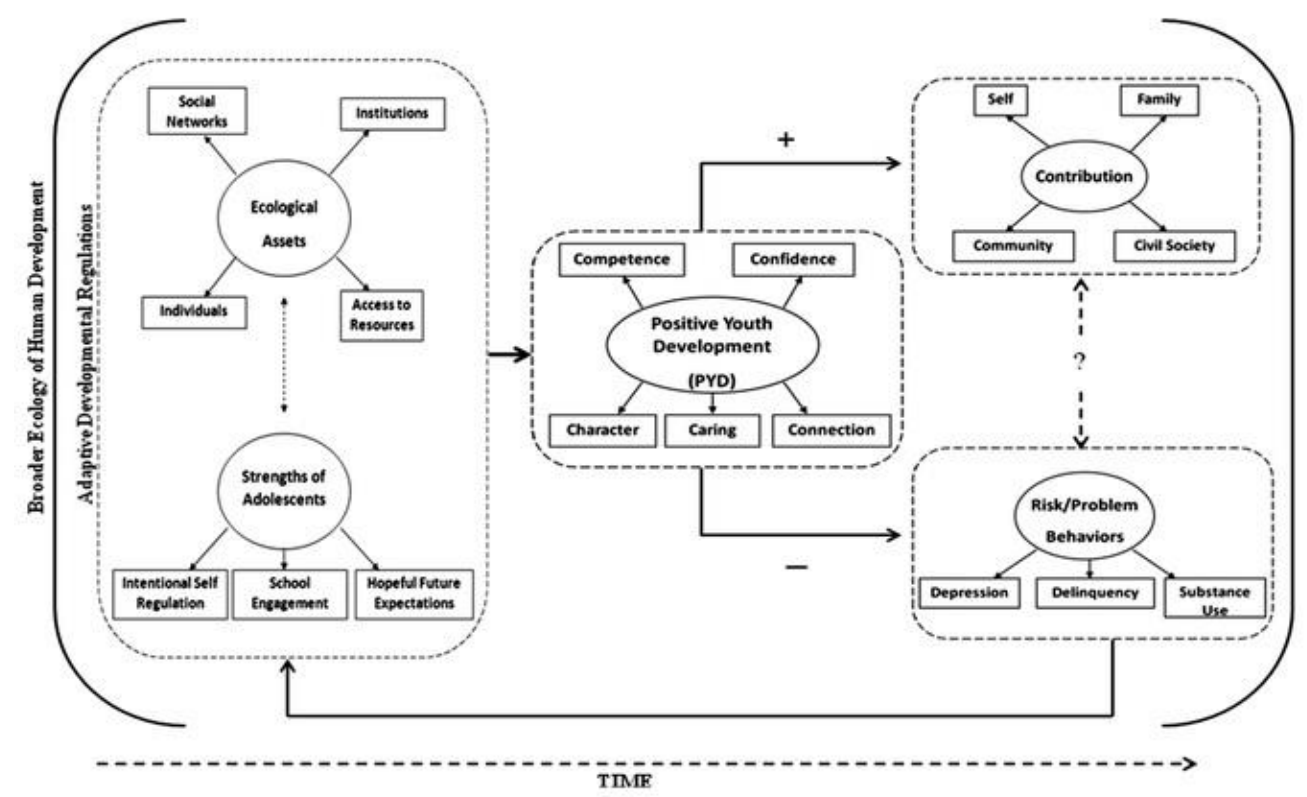

Figure 1: The relational, developmental systems model of Positive Individual involved in PYD (Lerner et al., 2005, p.7)

Theoretically, the ecological assets are associated with the developmental process of positive youths, consisting of the ' $5 \mathrm{Cs}$ ' (confidence, competence, character, caring, connection) that encourage positive behaviour among youths (Lerner, Brittian \& Fay, 2007). Based on the works of Lerner et al (2005), there are several specific steps that could be taken by mentors to develop all the five ' $C$ ' traits within their protégé. The theory of developmental systems posits that the changes in protégé development are assisted by mentors who 
prioritize positive development as a process whereby the individual and the context (related environment) are dynamically combined throughout the mutually beneficial interaction (Lerner, 2004: DuBois et al., 2011). When plasticity in human development is acknowledged, this will directly lead to building positive development of the individual's potential (Larson, 2006). Therefore, developmental system theory is also embedded in the youth development process, which is linked to positive youth development (Theokas, 2005).

Internal assets guide youth to make choices related to their strengths, such as future expectations, internal self-regulation and positive school engagement. External or ecological assets in one's environment include positive experiences with others, and the institutions with which youth are involved (Lerner et al., 2012). As earlier stated, when individual and external assets are maximized, the result is a positive, thriving individual with five core PYD outcomes referred to as the ' $5 \mathrm{Cs}^{\prime}$ ' (competence, confidence, character, connection and caring) (Lerner et al., 2005; 2015).

\section{Mentoring and Youth Leadership Qualities}

Generally, mentoring is a relationship between two parties, in which one party (the mentor) guides the other (the mentee) through a period of change and towards an agreed objective, or assists him or her to become acquainted with a new situation (Kay \& Hinds, 2012). Furthermore, leadership mentoring highlights the learning process of a one-to-one relationship, especially in traditional mentoring (Reagan-Porras, 2013), with the more senior and experienced individual as the mentor who supports the protégé's career development (Ragins \& Kram, 2007; Eller, Lev \& Feurer, 2013). Chaudhuri and Ghosh (2012), assert that traditional mentoring builds normative impression towards the process in which a mentor helps a mentee through a period of change.

Mentoring may take place in two situations, namely, formal and informal mentoring (Hezlett, 2005; DuBois et al., 2011), both with differences in learning development (Parise \& Forret, 2008; Pryce \& Keller, 2011). Through mentoring, youth are given the opportunity to develop their leadership skills and build relationships with their mentors. The advantage obtained by the youth through leadership mentoring is associated with the criteria of effective youth development. In addition, mentoring provides the opportunity for youth to gain access to ecological assets in the community in which they are involved. This will lead to the further attainment of the ' $5 \mathrm{C}$ ' outcomes, which eventually would be reflected in contributions made by the youth (Lerner et al., 2013).

The mentoring approach makes use of an enabler to encourage innovation, learning and continuous development (Kiltz, Danzig \& Szecsy, 2004). The dynamic mentoring theory contends that the principle of mentoring learning involves a close relationship between mentor and protégé, whereby the latter learns by observation and demonstration by the mentor (Balcazar \& Keys, 2013). Through mentoring, opportunities for gaining new experiences are made available at an exclusive level, by placing the protégé under another individual's supervision (Flores, 2011; Greeson, 2013).

According to Lerner et al. (2013), positive learning outcomes from mentoring is influenced by the support given by the mentor and experiences gained by the protégé. As such, youths require good role models to follow (Garcia, 2009). Hence, mentoring is a developmental 
process that requires involvement and commitment from both mentors and protégés (DuBois et al., 2011).

Mentoring may take place in two situations, namely, formal and informal mentoring (Hezlett, 2005; DuBois et al., 2011), both with differences in learning development (Pryce \& Keller, 2011). Kram's mentoring theory in Ragins and Kram (2007) assert that informal mentoring encourages protégé to learn to develop naturally towards what is known and based on priority. Meanwhile, in formal mentoring, protégé and mentor work together through a few processes with the support of an organization (Ragins \& Kram, 2007; Eby et al., 2013). According to Balcazar and Keys (2013), youth mentoring relationship becomes stronger when mentor and protégé consistently spend time together for a significant duration. Rhodes (2005), Rhodes and Dubois, (2008) and DuBois et al. (2011) suggest that learning through mentoring may contribute to the protégé's social-emotional, cognitive and identity development. The mentoring relationship is explained in Figure 2 below.

Figure 2: Youth Mentoring Model (Rhodes, 2005; Rhodes \& DuBois, 2008)

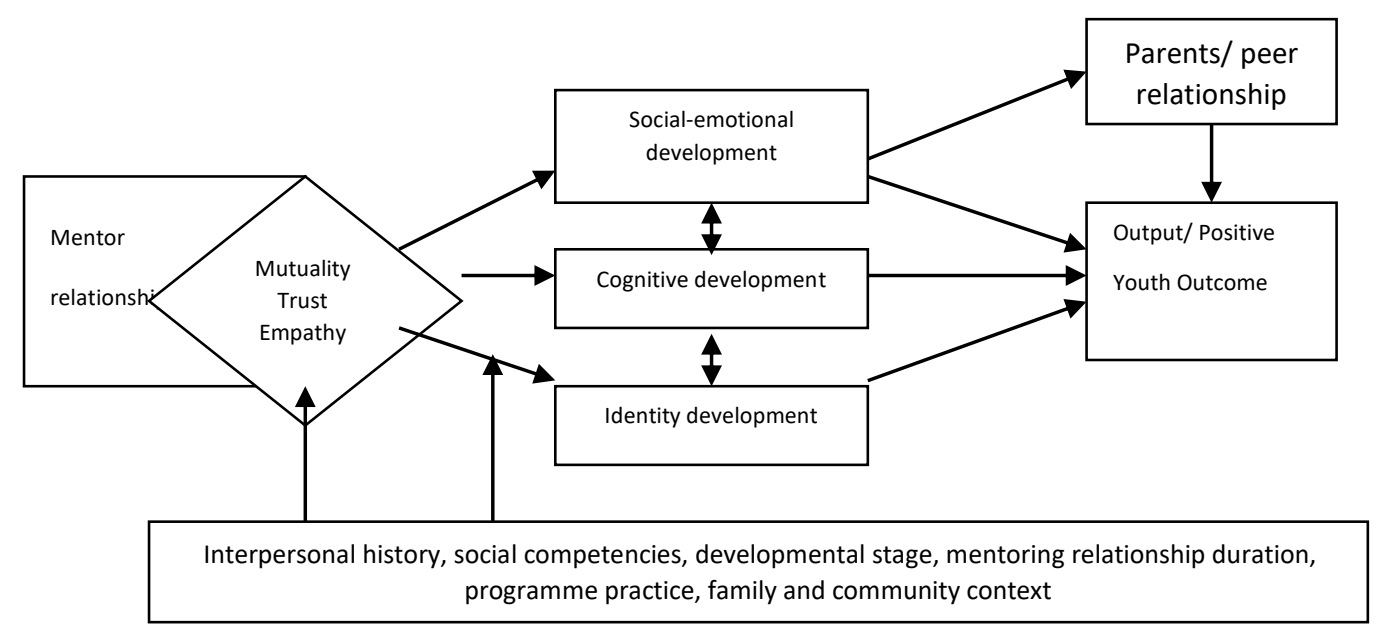

In this model, Rhodes and DuBois (2008) assert that positive experience from the socioemotional aspect in mentoring relationship may encourage youths to interact with others with an increased perception towards their parents, peers and adults within the protégés' social network more effectively. Besides that, the environmental factor between an individual, family and his/her surrounding also impacts the mentoring relationship and the process of nurturing positive youths (Rhodes, 2005). Therefore, youth leadership development through mentoring is relevant to positive youth development.

Through mentoring, youths are given the opportunity to develop and hone youth leadership skills, as well as maintain the relationship between them (protégé) and adults (mentor). The advantage obtained by youths through leadership mentoring is associated with the criteria of effective youth development. Other than that, it provides the opportunity for youths to gain wide access and connection using the ecological assets in the community they are involved in. This will directly lead to the formation of the ' $5 \mathrm{Cs}^{\prime}$ ' which are essential in developing youths who can contribute positively to the community (Lerner et al., 2007).

Protégés, who can easily adapt to any environment, including the mentoring environment, are viewed as individuals with the potential to elevate their self-development and eventually 
contribute towards positive development of family, the community and civil society (Theokas, 2005). Hence, mentoring is an important intervention to develop the potentials of youth. Figure 3 below illustrates the criteria required for youth development that may be embedded in the mentoring approach during the implementation of a developmental programme.

Figure 3: Effective Youth Development Model (Lerner et al., 2007)

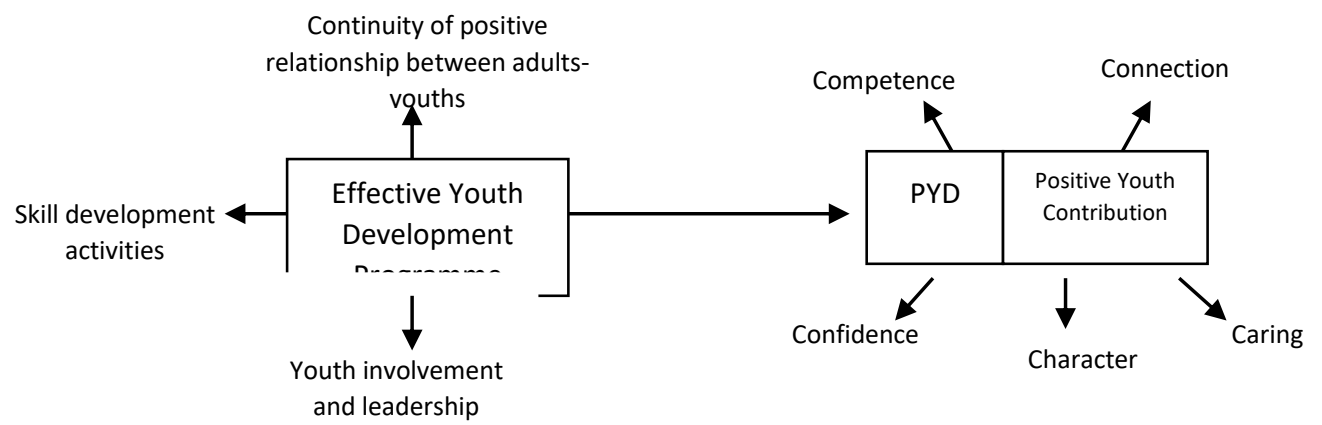

To cultivate and encourage both elements of PYD characteristics and positive youth contribution in youth development process, mentors need to play their roles in managing their interaction with protégés when mentoring so as to mirror three important aspects, namely skills development, youth leadership development, and relational continuity between adults and youths (Lerner et al., 2007). According to Siti Sarawati Johar et al (2020), the quality of a leader are based not only on his speech, but also on his body language, which must correspond to what is meant in his mind and soul and expressed in his actions. Therefore, learning from mentors includes emulating the behaviour or actions of mentors, inculcating charismatic values, and making a commitment towards positive transformation (Blass \& Ferris, 2007; Ragins \& Kram, 2007; Eby et al., 2013; Sanfey, Hollands \& Gantt, 2013). Effective mentoring enables the development of youth potential by providing opportunities for youths to build up various skills, especially leadership skills that will assist in their positive development (Lerner et al., 2013).

\section{Positive Youth Development Through Mentoring}

From the mentor-based youth leadership programme perspective, positive behaviours and attitudes (as a result of the knowledge formation process) are indicators of successful positive youth development through knowledge formation process, behaviour and positive attitude of the participants cultivated from the systematic program development (Lerner et al., 2005; Silbereisen \& Lerner, 2007; Lerner, Lerner, Lewin-Bizan, Bowers, Boyd, Mueller, Schmid, Napolitano, 2011). It is important to take into account the current needs of youth when planning youth development programmes (Cullen, Bradford \& Green, 2012). A proper planning of developmental programme should explain in detail the learning outcomes based on the objectives.

Effective mentoring enables the development of youth potential by providing them with the opportunity to develop life and leadership skills; positive youth development will, therefore, be enhanced (Lerner et al., 2013). Besides that, the environmental factor also impacts the mentoring relationship as they interact with others in their surroundings (Rhodes, 2005). The current study was conducted to explore the process of mentoring toward the realization of positive youth development and how the protégé's sense of contribution to the community 
and youth stakeholders would be enhanced through the mentoring process.

\section{Methodology}

A case study paradigm was used in this research that adopted a qualitative approach. Using the Malaysian national youth leadership development mentoring programme as the source for data collection, a total of 13 informants were involved in this study. They included mentors, protégés, the programme organizers and training providers, all of whom were identified by purposive sampling. The data were collected through in-depth, semi-structured interviews and supported with relevant information from group discussions, participant observations, document analysis, and field notes. The selection of participants for the study was based on the following criteria: a) informants were either protégés, mentors, organizers or training providers; b) protégés had achieved high scores on their assessments throughout the mentoring process; c) informants were willing to share learning experiences related to mentoring; and d) mentors were experienced in managing the mentoring processes. Snowball sampling was also carried out when participants introduced their friends to the study. Ultimately, the sample comprised those who were able and willing to provide the necessary information on the issues under study as suggested by Merriam \& Tisdell (2016) for purposive sampling strategy in qualitative research.

Initial data analysis was done immediately after the first interview. Various categories and themes were identified before the second interview was conducted. In order to foster a professional relationship between researchers and informants, the former established rapport to develop trust. First, the lead researcher moved into the field and identified a number of potential informants to be involved in the study. In several meetings, the researcher introduced the objectives of the study and sought the informants' consent to be involved in a series of in-depth interviews. To strengthen the reliability of data obtained from the informants, the researchers sought their permission and cooperation to carry out observations of their activities.

A total of 13 informants were involved in the study and the duration of each interview was between 50 minutes to 1 hour and 30 minutes. As suggested by Creswell and Poth (2018), data were collected until saturation point or data redundancy was achieved. Transcriptions of the interview sessions were examined several times in order to capture features of talk such as emphasis, speed, tone of voice, timing and pauses during interview. The data were further analyzed through coding and categorizing of themes using NVivo software.

Trustworthiness is a concept for determining whether this study is valid and reliable determining whether the study set out to investigate what it is supposed to. This study consisted of four main aspects, namely credibility, transferability, dependability and conformability. As suggested by Merriam and Tisdell (2016), validity can be achieved by making, a comparison between the descriptions and explanations, and whether these explanations fitted the description perfectly. Validity is a hallmark of qualitative research, determining whether the findings are accurate from the standpoint of the researcher, participant or reader (Creswell \& Poth, 2018).

In this study, validity was achieved through the use of audit trail, member checks and peer examination. An audit trail refers to the steps adopted by the researcher at every stage of data 
collection and analysis (Creswell \& Poth, 2018). Furthermore, the researcher needs to document the preparation of the proposal, construction of interview protocol and questions, data collection as well as the process of analysing the data. Member checks are used to reconnect the researcher to the informants to verify consistency in interpretation of the data (Silverman, 2013). The informants are subsequently contacted for clarification of facts of findings. As suggested by Creswell and Poth (2018), peer examination was also used to obtain feedback and consultation from a number of youth experts to verify data analysis and interpretation.

Exploring the phenomenon using qualitative research, we used the case study paradigm to examine youth's ability to conduct social activities, their exposure to community programme planning, and their mastery of soft skills as a result of mentoring. We investigated whether mentoring had the potential to develop various competencies among youth, especially leadership qualities.

\section{Findings and Discussion}

From verbatim transcripts and significant statements extracted, the findings showed how protégés developed their competencies through the mentoring process. In this study, the mentoring process was found to be unleashing youth leadership potentials in three ways: 1) encouraging learning agility 2) as a problem solver through solution-oriented practices; and 3) unleashing protégé's ability to delegate.

Successful implementation of special task requires youth leaders to approach the colleagues. Hence, they need to have leadership qualities as process helpers. There are several things that can be discovered from the informants on the causes for their involvement and engagement. Based on participant observation, mentoring provides opportunity for the protégé to communicate directly with their mentors. The study also found that protégés' access is not only limited only to getting input from their mentors, but the learning process also provided them with the opportunity to access other organizational members and took up the role as a project leader. Protégé 3 stated that:

"...I can practice on how to work with the community at a ground level. I had given this opportunity to lead in many projects under his (mentor) parliament, from urban to rural areas. Again, I was there and stayed for a certain period. My mentor wants me to learn with his officers and feel on how to lead. ...".

Findings community in organization also enhanced protégé's learning in the mentoring process. Mentor had given him a lot of opportunities to engage in planning to ensure that the needs of the young people are not brushed aside. Therefore, mentoring enables the protégé to easily adapt and contribute to the learning community. Guidance in 'learning the ropes' gained from community of practice facilitated the transfer of knowledge to protégés. Protégé 5 also said the same thing about leadership learning through empowerment from mentor:

“...Yes, my mentor's leadership style is empowering others. He really trust me to lead the project on behalf of him. At the same time, I need to build my rapport with his (mentor) staff. I also learnt many things from them 
(staff). He (mentor) gives this opportunity. So I need to adjust myself accordingly. He had (mentor) empowered me as his protégé, not command and conquer styles. So, I learnt on how to be a leader from the task. ...".

The study also found that the learner gains recognition as a member of a community and this community membership allows one to have the sense of belonging, engagement, inclusiveness and identity as a participant. Mentoring had provided greater access to other protégés in network construction while strengthening the network at the same time. Based on interview findings, protégés recognized the role of the mentor in providing the connection platform. As reported by Protégé 1:

"... feel like a family. Because all this people are like my parent, like my sisters. One day they can be like a brother and sister, like a dad and mom. So how closed we are. If you have the problem, you tell. If you feel like you can solve it, you will solve it. If you not, what should I do. Go and talk to this people. If you don't get to the minister, senior officer also like him (mentor). Get to speak to them and also get to learn. ..."

Based on participant observations, mentoring had provided opportunities for the protégés to develop their soft skills. Protégé 4 recognized the importance of strengthening his soft skills in the leadership mentoring process:

"...For me, soft skills help me to empathize with the community; I am constantly learning to hone my soft skills to be a better leader. While being mentored, I have had many opportunities to meet people, including those from remote areas. For example, when I meet new people, it is an opportunity to practise my soft skills. Like my mentor, I am now more committed to serving the community..."

Mentoring is a medium for linking protégés with stakeholders and other shareholders to create a wider network of partnerships. Protégé 2 stated that:

"... in the ministry, there are various parties and agencies that work together and assist the minister in implementing policies. I have indirectly involved my mentor in strengthening cooperation with others ... ".

During the mentoring process, the protégé was also involved in a series of discussions and negotiations with the mentor. Through such a platform, the protégé was able to build a wider network of disciplines requiring the same expertise. Protégé 3 stated that:

"...But when I saw my mentor who was so passionate about the leadership of these young people, so I started to engage. I started to meet, I felt I needed to go through this local youth leader. No matter what I say I have a great idea, they have a way... any idea or thing, easily through a local youth leader. ...". 
The advantages of leadership mentoring are in line with effective youth development criteria. According to the findings, throughout mentoring, youth are given the opportunity to develop skills, shape youth leadership and relational continuity, hence maintaining the connection between the youth (protégés) and their mentors. Besides that, it provides an opportunity for youth to gain access to ecological assets via the community they are involved in, and this will

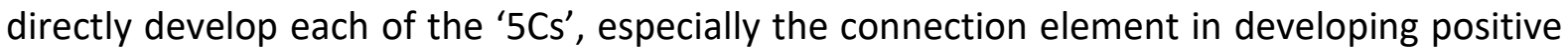
youth attributes (Lerner et al., 2011; Lerner et al., 2012).

Indirectly, the connection through mentoring enables the protégé to be easily identified by community leaders. Protégé 4 also said the same thing about leadership learning which, through connection with his mentor, enhanced his ability to delegate:

"... I feel I'm being empowered an exciting in coordinating task. During mentoring, I joined my mentor when he visited various areas in his constituency. Every time he went visiting, I would join him. Indirectly, I am was building up my soft skills, connection and networks with local leaders, community leaders and youth movement leaders as well. ... ".

The connection built by the protégé through his mentor had provided him the opportunity for his leadership skills to be recognized. A sense of accountability to the person being led is always instilled by the mentor. The responsibilities of good leaders must be based on prudent ways and approaches. Protégé 6 states:

"... The way we approach people of different ages. He doesn't see a gap. When there's no gap, people like it. Even when I see my mentor, I don't care what the people call him. He has no gap. He treats everyone. People came and saw that people liked him so much. ... ".

Access obtained from a mentor-owned network helps accelerate the development of ecological assets to improve PYD. Agans et al. (2014) state that youth are often left out in the context of social activities and positive connections. Therefore, the construction of an external network is necessary for youth to exhibit positive values that induce bonding with other individuals and institutions as well as helping to build up youth capacity (Agans et al., 2014). Provision of a platform by mentors helps to strengthen the bond in a mutually beneficial relationship between individuals and peers, institutions and communities.

Continuous soft skills development in leadership is also emphasized in the theory of leadership and soft skills; it includes enhancing the individual's ability to practise leadership in diverse activities and the ability to oversee subordinates (Alias et al., 2015). Based on findings, the benefits of youth leadership mentoring are associated with the effective youth development criteria. Besides that, it provides the opportunity for the youth to gain access through individual assets and this will directly develop each of the ' $5 \mathrm{Cs}$ ', especially competence trait (Lerner et al., 2011; Lerner et al., 2012).

\section{Discussions}

From the perspective of positive youth development and leadership development, it is a process of preparing youth to meet challenges as a leader and developing individual and 
ecological assets that augment their skills and competencies, thus enabling them to be more effective. According to Lerner et al. (2005), the dynamic mentoring involves a close relationship between mentors and protégés, whereby the protégés' learning is based on their observation of the mentor's demonstrations and learning support (Lerner et al., 2005). Learning becomes more meaningful in the social and physical context in the situated contexts (Lave, 1988; Lave \& Wenger et al., 2002), when there is interdependence among activities, concept and culture (Brown, Collins, \& Duguid, 1989; DuBois et al., 2011; Pryce \& Keller, 2013). Therefore, learning methods in leadership development process is also dependent on organisational culture that may influence leadership style (Holt, Bjorklund \& Green, 2009; Caldwell \& Dixon, 2010; Dukeworth et al., 2019).

The mentoring method has been shown to be an effective platform to develop youth leadership through access to networking with role models, as well as expand social networks, and access to resources which are the elements in the ecological asset as discussed by Lerner et al. (2005). In mentoring, the protégé is able to potentially acquire knowledge and leadership skills from his or her mentor, both formally and informally. Hence, youth developmental programmes, especially those focusing on leadership, require continuous effort from various parties to nurture quality human capital to prepare for the future. According to Li and Wang (2009), youth involvement in leadership activities is one of the approaches in the PYD concept. The focus on PYD is the basis to developing positive youth elements (Ward, 2008), which principally requires empirical understanding to uncover youth mentoring potentials in PYD development through leadership.

Therefore, the first step to apply PYD elements in mentoring is by employing the approach as suggested by Delgado (2002). It involves identifying the needs of protégés and then building up the competencies needed to become successful adults by not dismissing them as individuals without potential (Hastings et al., 2011). The next step is for mentors to delve into their protégés' ability as a resource that can be developed and strengthened i.e. their protégés should be nurtured to become effective leaders. This approach is in line with Lerner et al.'s (2013) who recommend PYD as an approach to develop youth potential. The third step is to build up the leadership developmental process where both parties, namely the mentors and protégés, collaboratively decide on the potentials to be developed and supported (Lerner et al., 2005). Through this approach, the community can contribute to youth leadership development in a positive way, through mentoring (Lerner et al., 2011; Redmond \& Dolan, 2016).

The next step is for mentors to play their roles responsibly by providing their protégés some space for themselves to easily adapt to different environments and situations. The influence that mentors have on their protégés during the mentoring process allows youths to be seen as individuals with the potential to develop themselves and contribute to civil society (Theokas, 2005). Leadership mentoring gives youth leaders the opportunity to make themselves worthy through their contributions to the community, based on the application of PYD elements (Benson, Scales \& Syvertsen, 2011). Mentors should ensure that the form of interaction with their protégé in mentoring mirrors three aspects, namely skills development, leadership development, and relationship continuity, even after they have ended their formal mentoring. 
However, the mentoring process is not just a simple or easy knowledge transmission to measure in the form of skills, since it also focuses on how far true leadership quality incorporates the PYD elements in youth development processes. Therefore, the utmost priority is to ensure effective mentoring is incorporated in the development of youth leadership so that the process of producing new leadership talents among youths can be implemented accordingly. Dynamic management and youth resource development will continue the leadership legacy to ensure that the country's future development agenda is led by high-calibre leaders.

Leadership mentoring is one of the more insightful mechanisms that helps in developing leadership abilities among youth. Therefore, more effort should be made to explore Malaysian youths' involvement in leadership development via mentoring, which contributes to the overall positive youth development. These efforts ultimately elevate positive values of youth. It can be seen that the mentoring builds strong relationships between among young leaders and their role models. Youth leadership development is about identifying and developing young talents, unleashing the potentials of future leaders to enable them to contribute more effectively towards nation-building.

\section{Conclusion}

Previous studies suggest that mentoring can assist in the grooming of youth leaders but few studies have explored how this occurs. This research was conducted to explore how youth who participated in leadership programmes that incorporate mentoring, are nurtured to inculcate positive traits promoted by PYD. The study findings indicated that competence development occurred not only during mentoring, but also in the locus of the mentor's organizational community. Thus learning and connection were not limited only to what occurred within the one-to-one mentor-protégé dyad. The implication of study discussed that traits characterised by the '5Cs' in Positive Youth Development (PYD) were developed and strengthened through mentoring.

The effectiveness of youth mentoring programmes is also directly dependent on the planning of leadership development programmes. The ability of mentoring techniques in developing youth leadership can be seen more clearly if the process of knowledge development, attitude and practice are cultivated to engender a deeper understanding in a case study. To empower mentoring potential, mentors are encouraged to play their role of guiding youth leaders by connecting them to other social networks so as to expose them to other established institutions. Wider exposures, for example, in societal leaderships, and regional organizational bodies at the international level could prepare youth leaders as resource connector agents.

\section{References}

Agans, J. P., Champine, R. B., DeSouza, L. M., Mueller, M. K., Johnson, S. K., \& Lerner, R. M. (2014). Activity involvement as an ecological asset: Profiles of participation and youth outcomes. Journal of Youth and Adolescence, 43, 919-932.

Alias, R., Ismail, M. H., \& Sahiddan, N. (2015). A measurement model for leadership skills using Confirmatory Factor Analysis (CFA). Procedia - Social and Behavioral Sciences, 172, 717-724. 
Balcazar, F. E., \& Keys, C. B. (2013). Goals in mentoring relationship. In D. L. DuBois, \& M. J. Karcher (Eds.), The handbook of youth mentoring (2nd ed.). (pp. 83-98). Thousand Oaks: Sage Publications Inc.

Benson, P. L., Scales, P. C., Hamilton, S. F., \& Sesma, A., Jr. (2006). Positive youth development: Theory, research, and applications. In R. M. Lerner (Ed.), Theoretical models of human development. Volume 1 of Handbook of Child Psychology (6th ed.) (pp. 894-941). Editors-in-chief: W. Damon \& R. M. Lerner. Hoboken, NJ: Wiley.

Benson, P. L., Scales, P. C., \& Syvertsen, A. K. (2011). The contribution of the developmental assets framework to positive youth development theory and practice. In R. M. Lerner, J. V. Lerner, \& J. B. Benson (Eds.), Advances in child development and behavior (pp. 125228). Elsevier Publishing.

Blass, F. R., \& Ferris, G. R. (2007). Leader reputation: The role of mentoring, political skill, contextual learning, and adaptation. Human Resource Management, 46(1), 5-19.

Brown, J. S., Collins, A., \& Duguid, P. (1989). Situated cognition and the culture of learning. Educational Researcher, 18(1), 34-41.

Caldwell, C., \& Dixon, R. D. (2010). Love, forgiveness, and trust: Critical values of the modern leader. Journal of Business Ethics, 93, 91-101.

Christens, B. D., \& Dolan, T. (2011). Interweaving youth development, community development, and social change through youth organizing. Youth \& Society, 43, 528-548.

Creswell, J. W. \& Poth, C. (2018). Qualitative inquiry and research design: Choosing among five approaches (4th ed.). Thousand Oaks, CA: Sage Publications Inc.

Cullen, F., Bradford, S., \&, Green, L. (2012). Working as a Practitioner - Researcher . In Bradford, S., \& Cullen, F. (Eds.), Research and Research Method for Youth Practitioners (pp.90-112). Oxon: Routledge.

Delgado, M. (2002). New frontiers for youth development in the twenty-first century revitalizing youth development. New York: Columbia University Press.

Duckworth, C., Albano, T., Munroe, D., \& Garver, M. (2019). Students can change a school": Understanding the role of youth leadership in building a school culture of peace. Conflict Resolution Quarterly 36(3), 235-249.

Chaudhuri, S., \& Ghosh, R. (2012). Reverse mentoring: a social exchange tool for keeping the boomers engaged and millennials committed. Human Resource Development Review, 11, 55-76.

DuBois, D. L., Portillo, N., Rhodes, J. E., Silverthorn, N., \& Valentine, J. C. (2011). How effective are mentoring programs for youth?: A systematic assessment of the evidence. Psychological Science in the Public Interest, 12(2), 57-91.

Eby, L. T., Allen, T. D., Hoffman, B. J., Baranik, L. E., Sauer, J. B., Baldwin, S., Morrison, M. A., Kinkade, K. M., Maher, C. P., Curtis, S., \& Evans, S. C. (2013). An interdisciplinary metaanalysis of the potential antecedents, correlates, and consequences of protégé perceptions of mentoring. Psychological Bulletin,139(2): 441-476.

Eller, L. S., Lev, E. L., \& Feurer, A. (2013). Key components of an effective mentoring relationship: A qualitative study. Nurse Education Today, 13(1), 1-6.

Flores, E. M. (2011). Becoming a Researcher: A Qualitative Study of the Apprenticeship Model in Doctoral Education. PhD Thesis, University of Washington.

Garcia, C. P. (2009). Leadership lessons of the white house fellows. New York: McGraw Hill.

Gestsdottir, S., Urban, J. B., Edmond, P., Lerner, J. V, \& Lerner, R. M. (2011). Intentional SelfRegulation, Ecological Assets, and Thriving in Adolescence: A Developmental Systems Model. In R. M. Lerner, J. V. Lerner, E. P. Bowers, S. Lewin-Bizan, S. Gestsdottir, \& J. B. 
Urban (Eds.), Thriving in childhood and adolescence: The Role of self-regulation processes. New Directions for Child and Adolescence Development, 133, 61-76.

Greeson, J. K. P. (2013). foster youth and the transition to adulthood: The theoretical and conceptual basis for natural mentoring. Emerging Adulthood, 1(1), 40-51.

Hastings, L. J., Human, N., \& Bell, L. C. (2011). Developing a paradigm model of youth leadership development and community engagement : A Grounded Theory. Journal of Agricultural Education, 52(1), 19-29.

Hezlett, S. A. (2005). Protégés learning in mentoring relationships: A review of the literature and an exploratory case study. Advances in Developing Human Resources, 7(4), 505-526.

Hofstede, G., \& Hofstede, G. J. (2005). Cultures and organizations: Software of the mind (2nd ed.). New York: McGraw-Hill.

Hofstede, G., \& Hofstede, G. J. \& Minkov, M. (2010). Cultures and organizations: Software of the mind. Cultures and Organizations. New York: MacGraw-Hil.

Holt, S., Bjorklund, R., \& Green, V. (2009). Leadership and culture: Examining the relationship between cultural background and leadership perceptions. The Journal of Global Business Issues, 3(2), 149-164.

Jogulu, U. D. (2010). Culturally-linked leadership styles. Leadership \& Organization Development Journal, 31(8), $705-719$.

Johar, S. S., Lestari, L., \& Awada, N. (2020). The art of leadership qualities in human governance of human capital. Journal of Management Practices, Humanities and Social Sciences, 4(1), 12-15.

Kay, D., \& Hinds, R. (2012). A practical guide to mentoring: Using coaching and mentoring skills to help others achieve their goals (5th ed.). Oxford: How to Books Ltd.

Khan, R. A., Ahmad, M. S., \& Khan, R. U. (2019). Service-Learning for youth leadership. Applied Research Quality Life.

Khatri, N. (2009). Consequences of power distance orientation in organisations. The Journal of Business Perspective, 13(1), 1-9.

Kiltz, G., Danzig, A., \& Szecsy, E. (2004). Learner-centered leadership: a mentoring model for the professional development of school administrators. Mentoring \& Tutoring: Partnership in Learning, 12(2), 135-153.

Larson, R. (2006). Positive youth development, willful adolescents and mentoring. Journal of Community Psychology, 34(6), 677-689.

Lave J. (1988). Cognition in practice: Mind, mathematics and culture in everyday life. New York, NY: Cambridge University Press.

Lave, J., \& Wenger, E. (1991). Situated learning: Legitimate peripheral participation. Cambridge: Cambridge University Press.

Lerner, R. M., Lerner, J. V., Almerigi, J., Theokas, C., Phelps, E., Gestsdottir, S., Naudeau, S., Jelicic, H., Alberts, A. E., Ma, L., Smith, L. M., Bobek, D. L., Richman-Raphael, D., Simpson, I., Christiansen, E. D., \& Von Eye, A. (2005). Positive youth development, participation in community youth development programs, and community contributions of fifth grade adolescents: Findings from the first wave of the 4-H study of positive youth development. Journal of Early Adolescence. 25(1): 17-71.

Lerner, R. M., Brittian, A., \& Fay, K. (2007). Mentoring: A key resource for Promoting positive youth development. Research in Action, 1(1), 3-15.

Lerner, R. M., Von Eye, A., Lerner, J. V., Lewin-Bizan, S., \& Bowers, E. P. (2010). The meaning and measurement of thriving: A view of issues. Journal of Youth and Adolescence, 39 (7), 707-719. 
Lerner, R. M., Lerner, J. V., Lewin-Bizan, S., Bowers, E. P., Boyd, M., Mueller, M., Schmid, K., Napolitano, C. (2011). Positive youth development: Processes, programs, and problematics. Journal of Youth Development, 6(3), 40-64.

Lerner, R. M., Bowers, E. P., Geldholf, G. J., Gestsdottir, S., \& Desouza, L. (2012). Promoting positive youth development in the face of contextual changes and challenges: The roles of individual strengths and ecological assets. New Directions for Youth Development, 135(1), 119-28.

Lerner, R. M., Napolitano, C. M., Boyd, M. J., Mueller, M. K., \& Callina, K. S. (2013). Mentoring and positive youth development. In D. L. DuBois, \& M. J. Karcher (Eds.), The handbook of youth mentoring (2nd ed.). (pp. 17-27). Thousand Oaks: Sage Publications Inc.

Lerner, R. M., Lerner, J. V., Bowers, E. P., \& Geldholf, G. J. (2015). Positive youth development: A relational developmental systems model. In R.M. Lerner, W. F. Overton, \& P. C. M. Molenaar (Eds.), The handbook of child psychology and developmental science (7th ed.). (pp. 607-651). New Jersey: John Wiley and Sons Inc.

Malaysian Youth Index: Outcome Study. (2019). Institut Penyelidikan Pembangunan Belia Malaysia. Putrajaya: Kementerian Belia dan Sukan Malaysia.

Merriam, S. B., \& Tisdell, E.J. (2016). Qualitative research: A guide to design and implementation (4th ed.). San Francisco, CA: Jossey-Bass.

Phelps, E., Zimmerman, S., Warren, A. E. A., Jeličič, H., von Eye, A., \& Lerner, R. M. (2009). The structure and developmental course of Positive Youth Development (PYD) in early adolescence: Implications for theory and practice. Journal of Applied Developmental Psychology, 30(5), 571-584.

Pryce, J. M., \& Keller, T. E. (2011). Interpersonal tone within school-based youth mentoring relationships. Youth \& Society, 45(1), 98-116.

Ragins, B. R., \& Kram, K. E. (2007). The roots and meaning of mentoring. In B. R. Ragins, \& K. E. Kram (Eds.), The handbook of mentoring at work: Theory, research and practice (pp. 317). Thousand Oaks: Sage Publications Inc.

Reagan-Porras, L. L. (2013). Dynamic duos: A case review of effective mentoring program evaluations. Journal of Applied Social Science, 7(2), 208-219.

Rhodes, J. E. (2005). A model of youth mentoring. In D.L. DuBois \& M.J. Karcher (Eds.), Handbook of youth mentoring (pp. 30-43). Thousand Oaks, CA: Sage.

Rhodes, J. E., \& Dubois, D. L. (2008). Mentoring relationships and programs for youth. Current Directions in Psychological Science, 17(4), 254-258.

Redmond, S., \& Dolan, P. (2016). Towards a conceptual model of youth leadership development. Child \& Family Social Work. 21(3), 261-271.

Sanfey, H., Hollands, C., \& Gantt, N. L. (2013). Strategies for building an effective mentoring relationship. American Journal of Surgery, 206(5), 714-8.

Seemiller, C. (2019). A competency-based model for youth leadership development. Journal of Leadership Education, 56-72.

Shek, D. T. L., Dou, D., Zhu, X., \& Chai, W. (2019). Positive youth development: current perspectives. Adolescent Health, Medicine and Therapeutics, 10 (1), 131-141.

Silbereisen, R. K., \& Lerner, R. M. (2007). Approaches to positive youth development. London: Sage Publications.

Silverman, D. (2013). Doing qualitative research: A practical handbook. Thousand Oaks: Sage Publications Inc.

Theokas, C. (2005). Conceptualizing and modeling individual and ecological asset components of thriving in early adolescence. The Journal of Early Adolescence, 25(1), 113-143. 
Ward, P. J., \& Ellis, G. D. (2008). Characteristics of youth leadership that influence adolescent peers to follow. Journal of Park and Recreation Administration, 26(2), 78-94.

Wenger, E., McDermott, R., \& Snyder, W. M. (2002).Cultivating communities of practice. Boston: Harvard Business School Press.

Youth Societies and Youth Development Act (Amendment) Act 668. (2019). Retrieved from https://www.cljlaw.com/files/bills/pdf/2019/MY_FS_BIL_2019_12.pdf.

Zeldin, S., Gauley, J., Krauss, S. E., Kornbluh, M., \& Collura, J. (2017). Youth-Adult partnership and youth civic development: cross-national analyses for scholars and field professionals. Youth \& Society, 49(7), 851-878. 